\title{
Role of Land-Atmosphere Interaction on Asian Monsoon Climate
}

\author{
Tetsuzo YASUNARI \\ Hydrospheric Atmospheric Research Center (HyARC), Nagoya University, Nagoya, Japan \\ Frontier Research Center for Global Change (FRCGC), JAMSTEC, Yokohama, Japan
}

(Manuscript received 1 June 2007, in final form 7 June 2007)

\begin{abstract}
This paper has discussed the land-atmosphere interaction associated with the Asian monsoon climate and its variability. The snow cover and soil moisture are internal factors of the climate system particularly in the seasonal to interannual time scales, but are suggested to play some important roles in changing large-scale surface energy and water balance, which in turn affect the monsoon circulation and precipitation. From the modeling as well as observational studies it has been suggested that the snow cover is most likely to influence atmosphere essentially through the albedo effect particularly in lower latitudes and on the Tibetan Plateau. The GCM experiments have strongly suggested that soil moisture anomalies efficiently affect the atmosphere under dry or semi-arid condition. Vegetation has also been noted as an important variable for the formation of moist monsoon flow over the continent, in addition to the dynamical and thermo-dynamical effect of the Tibetan Plateau.

Through the GCM and RCM experiments the anthropogenically-induced change of land cover/use including the deforestation has proved to be a great impact on regional precipitation and water cycle of the monsoon region by changing characteristics of vegetation control in energy and water cycle, which in turn affect atmospheric boundary layer (ABL) and cloud/precipitation processes in regional-scale. The discussion has also been made on how the land surface changes could induce change of precipitation through feedback processes of moisture convergence and in-situ evapo-transpiration processes. The critical role of moisture amount near surface and in the ABL is emphasized, to induce positive feedback to change of precipitation over land in the monsoon region.
\end{abstract}

\section{Introduction}

The monsoon is manifested as a landatmosphere-ocean interaction between continents and oceans in the seasonal cycle. The ocean has large heat content with longer climate memory of more than a year, while the land has small heat content and its climate memory is believed to be short (of less than a season). Some of the recent model studies emphasized relative importance of the oceanatmosphere interaction (O-AI) compared to

Corresponding author: Tetsuzo Yasunari, Hydrospheric Atmospheric Research Center (HyARC), Nagoya University, Nagoya, Aichi 464-8601, Japan.

E-mail: yasunari@hyarc.nagoya-u.ac.jp

(C) 2007, Meteorological Society of Japan land-atmosphere interaction (L-AI), particularly focusing on the strong impact of largescale sea surface temperature (SST) anomalies in the tropical oceans nearby the continent. It should be noted, however, that to specify or distinguish the roles of L-AI from those of O-AI and vice versa is very difficult or, may be nonsense, particularly in the Asian-Australian monsoon system, because these two processes are strongly coupled to each other. In other words, the L-AI (or O-AI) in the monsoon system should, in any case, be understood as part of the full land-atmosphere-ocean interaction. In this review I will discuss some current issues on the role of L-AI on the Asian monsoon climate with its seasonal cycle, interannual variability and long-term change including anthropogenic impact, based on some recent ob- 
servational as well as climate modeling studies, by updating the discussion made in Yasunari (2006).

\section{Fundamental land surface processes controlling Asian monsoon climate}

The physical quantities of land surface which may posses anomalous atmospheric forcing or climate memory effect can be 1) snow cover, 2) soil moisture, and 3) vegetation. The land surface layer is generally thought to have small heat capacity compared to the ocean surface layer, the non-linear processes of these quantities in the seasonal and interannual variations effectively produce relatively longer memory effect, even compatible to that of SST as shown in Fig. 1 (Walsh et al. 1985; Shinoda and Gamo 2000). The seasonal and interannual variability of these quantities play significant role in land-atmosphere interaction by producing anomalous surface and atmospheric heating or cooling, which in turn affects the monsoon circulation and convection. One should keep in

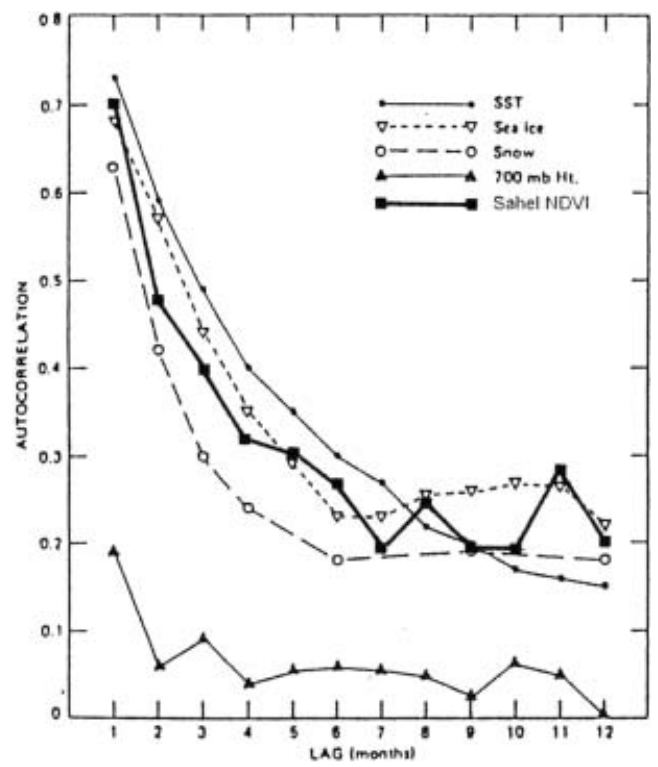

Fig. 1. Autocorrelations of monthly anomaly of SST in the northern Pacific, sea ice in the Arctic Sea, snow cover over Eurasia, geopotential height at $700 \mathrm{hPa}$ depicted from Walsh et al. (1985) and NDVI in Sahel region, North Africa obtained from Shinoda and Gamo (2000). (Shinoda et al. 2003) mind that these quantities are interactive with the atmospheric conditions so that detection of simple cause-result relation is sometimes difficult. However, due to lack of the adequate observational data, and lack of understanding of actual physical processes particularly relevant to the climate studies, large uncertainties still exist in the relation between variabilities of these quantities and monsoon activity. Comprehensive and interactive observation and modeling strategy is really important for this study.

\subsection{Role of continental snow cover}

The snow cover has several effects on producing anomalous atmospheric conditions as follows: a) albedo effect controlling incoming solar radiation, b) insulation of heat between the atmosphere and land surface by snow mass of small heat conductivity, c) heat sink effect by melting process, and d) water source by melting process (Shinoda et al. 2003). The first three effects can work to change surface energy transfer process while snow cover exists on the surface. Only the fourth effect possibly has a climate memory even after snowmelt, by affecting soil moisture content near the surface which is called "snow-hydrological effect" as shown in Fig. 2 (Yasunari et al. 1991).

The data sets for validating these effects of snow cover are still limited. Most of the observational studies have been made based on the snow cover extent (of frequency) data from the NOAA operational meteorological satellites. Some studies also used ground-based snow depth measurement for limited areas (e.g., the former USSR, USA, Canada etc.). The continental-scale snow mass (water equivalent depth) information retrieved from satellitebased microwave data has become available for the recent one or two decades (e.g., Koike et al. 2001) though some accuracy problems still exist due to biases from vegetation and melting processes.

Blanford (1884) first noted the relationship between the Himalayan winter snow cover anomaly and the succeeding All-India Monsoon rainfall (AIMR). Walker (1910) followed up his study and re-confirmed this negative correlation. Since the 1960s the satellite-based snow cover extent data became available, and so many studies have addressed this issue as a typical example of the role of L-AI on the inter- 


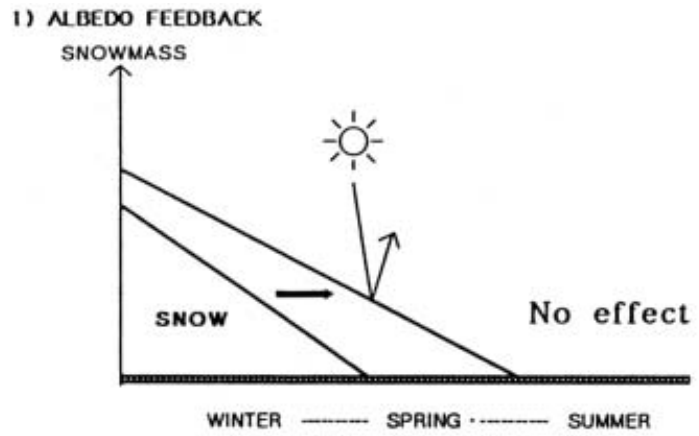

2) SNOW HYDROLOGICN FEEDBACK

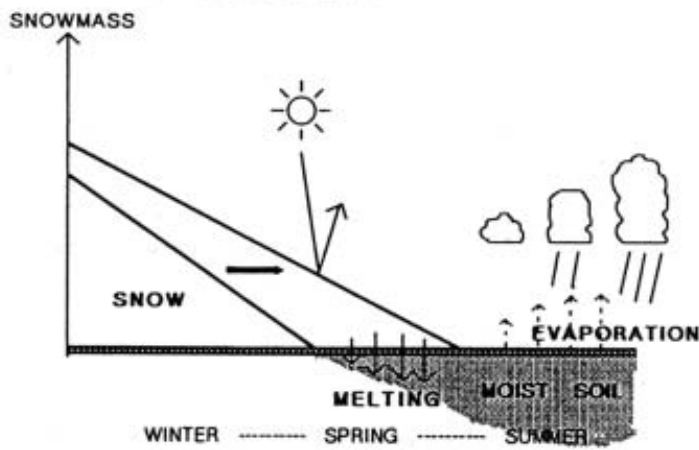

Fig. 2. Schematic diagrams for (1) the albedo feedback and (2) the hydrological feedback of snow cover during the seasonal march from winter to summer. (Yasunari et al. 1991)

annual variability of Asian monsoon. Hahn and Shukla (1976) showed an apparent negative correlation between the satellite-based winter snow cover extent anomaly over Eurasia and the following AIMR, though the data used were only 9 years (Fig. 3). Since then numerous similar studies have been done using some different indices of snow cover for winter and/or spring, and some different indices of the Indian or Asian summer monsoon activity (Dey and Bhanu Kumar 1982; Dickson 1984; Bhanu Kumar 1987, 1988; Chattopadhay and Singh 1995; Kripalani et al. 1996, 2003; Shankar-Rao et al. 1996; Morinaga et al. 1997, 2000; Bamzai and Shukla 1999; Kripalani and Kulkarni 1999; Robock et al. 2003). Some studies also discussed Eurasian snow-AIMR relationship, as part of ENSO-monsoon connections (Yasunari 1987; Kahndekar 1991; Yasunari and Seki 1992; Yang 1996; Yang and Lau 1998; Kawamura 1998; Ye and Bao 2001; Liu and Yanai

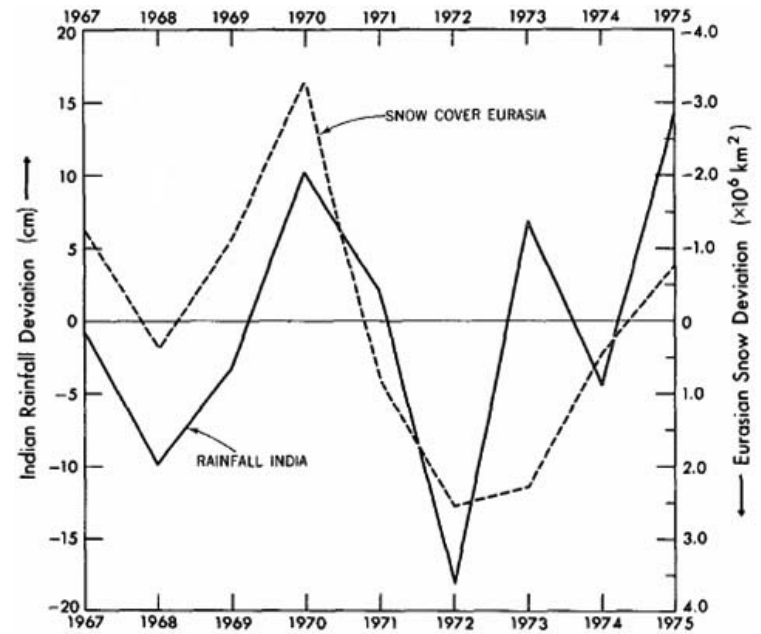

Fig. 3. Year-to-year variations of the All India Monsoon Rainfall and snow cover area over central part of Eurasia north of $52^{\circ}$. (Hahn and Shukla 1976)

2002). Some of these studies concluded that the snow cover-AIMR correlation might be resulted from a common large-scale atmospheric circulation pattern that is responsible both for the snow cover anomaly and the AIMR anomaly. One possible idea is that ENSO-related teleconnection induces anomalous atmospheric circulation over Eurasia, which may fundamentally be responsible for anomalous Asian summer monsoon activity (Webster et al. 1998). The snow cover anomaly induced by the anomalous circulation may partly reinforce to produce weaker monsoon through radiation and energy flux processes as suggested in the observational study (Yang et al. 2004) and in a GCM experiment (Shen et al. 1998).

A central issue for the snow cover-AIMR connection may be how the climate memory of snow cover in winter (or spring) anomaly can be conveyed to the following summer. Some GCM studies attempted to this issue (Barnett et al. 1989; Yamazaki 1989; Yasunari et al. 1991; Vernekar et al. 1995; Douville and Royer 1996). Though some of these GCM experiments have given unrealistically large anomalous snow cover (snow mass) as an initial condition, both the albedo and the snow-hydrological effect of anomalous snow cover could play, to some extent, to produce monsoon anomalies in summer. Some studies emphasized that the 
albedo and snow-melting effect on the Tibetan Plateau in spring showed relatively large impact on weakening the summer monsoon through suppressing net radiation and sensible heat flux (Yasunari 1991; Douvelle and Royer 1996). In contrast, a recent large-ensemble GCM experiment has suggested that in the northern part of the continent (e.g., Siberia), snow-mass anomaly may be more important for producing atmospheric anomaly than snow cover (albedo) forcing (Gong et al. 2004). Takata and Kimoto (2000) pointed out the importance of seasonal freezing (and melting) of surface permafrost layer in the northern part of the continent on thermal and hydrological processes of the surface. Full inclusion of these processes causes higher surface temperature (due to suppressed evaporation) and stronger monsoon circulation in Southeast Asia. The observational study (Ohta et al. 2001) of seasonal surface energy and water flux in East Siberia conducted as part of GAME-Siberia partly supported the important processes noted by Takata and Kimoto (2000).

The precise observational studies on seasonal march of temperature and circulation field over Eurasia from spring to summer, however, have shown that the influence of snow cover and related soil moisture anomaly on the temperature and circulation anomalies in the lower troposphere is limited primarily when and where snow cover exists seasonally as schematically shown in Fig. 4 (Shinoda et al. 2001; Ueda et al. 2003; Robock et al. 2003). The long-term surface energy flux observation on the Tibetan

Fig. 4. Latitude-time sections showing (a) mean (1966-90) seasonal evolution of the surface temperature (degrees Celsius) along a longitude of $30-60^{\circ} \mathrm{E}$. Thick black contour indicates surface temperature $0^{\circ} \mathrm{C}$. The dashed contour denotes climatological snow-disappearance pentads. (b) The same as in (a), except for $850 \mathrm{hPa}$ horizontal wind obtained from ECMWF reanalysis (198090). The southerly wind component greater than $1 \mathrm{~m} \mathrm{~s}^{-1}$ is denoted by twotone shadings. (c) The same as in (a), but for static stability $\gamma$ between 850 and $700 \mathrm{hPa}$. Shading is region of $\gamma$ less than $5.0 \mathrm{~K} \mathrm{~km}^{-1}$. (Ueda et al. 2003)
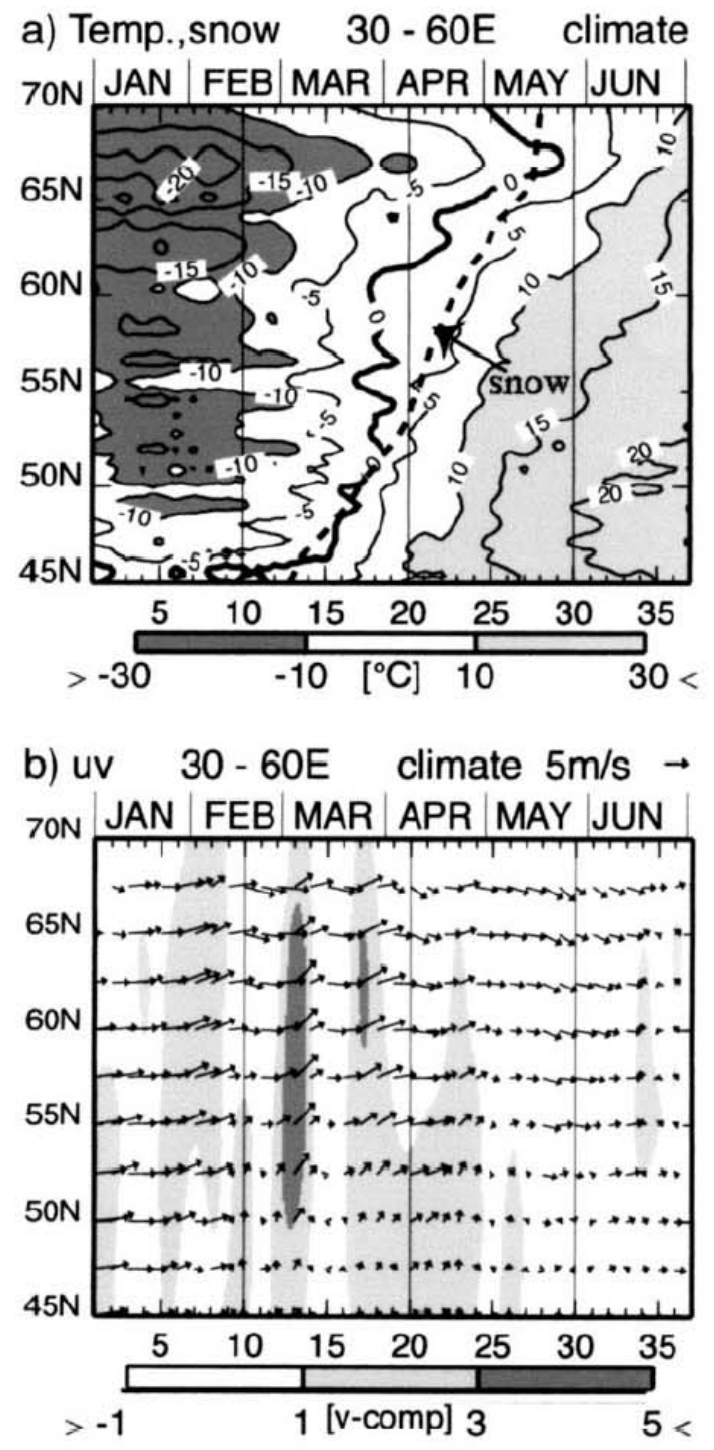

c) $\gamma(700-850) \quad 30-60 \mathrm{E}$ climate

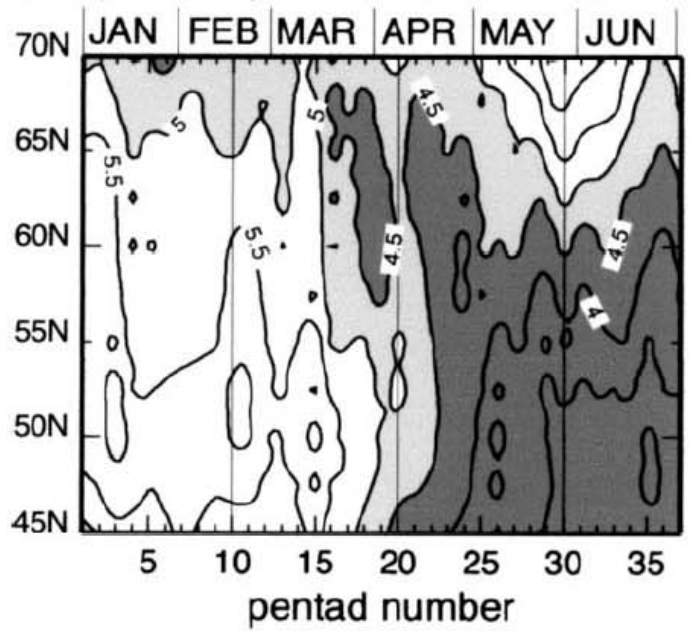


Plateau as part of GEWEX Asian Monsoon Experiment (GAME) in 1998 suggested that the anomalous heavy snow cover in spring on the central Plateau resulted in considerable decrease of sensible heating and delayed monsoon onset over the Plateau (Tanaka et al. 2004).

\subsection{Role of soil moisture}

The soil moisture is a key parameter for L-AI in the climate system. The anomaly of surface and near-surface soil moisture is likely to have persistence of several days to several months, which may cause climate memory through anomalous surface energy and moisture fluxes. However, this quantity is very difficult to measure adequately. The long-term in-situ measurement of soil moisture is very limited both in time and space (Robock et al. 1998, 2000). The recent satellite-based indirect measurement using microwave sensors is a promising method for large-scale soil moisture monitoring, but it has still been limited for soil moisture or wetness of very-near surface soil layer. The climate memory effect of soil moisture has, therefore, been discussed basically based upon climate model experiments.

Delworth and Manabe $(1988,1989)$ firstly assessed the climate memory effect of soil moisture in GCMs using the so-call bucket model (Manabe 1969) interacting with the atmosphere through surface water balance. Their bucket model consists of one soil layer with $15 \mathrm{~cm}$ water holding capacity (field capacity). They noticed that the persistency (measured by auto-correlation) of soil moisture anomaly is small whereas in higher latitudes this value is large, depending upon the ratio of $P / E p$ ( $P$ : Precipitation, $E p$ : Potential Evapo-transpiration) as shown in Fig. 5. In the humid tropics or monsoon regions where $P$ is large enough to saturate the soil layer, soil moisture anomaly does not make sense as a climate memory. The distribution of persistency in Fig. 5 can be generally described in the form $1 / \lambda=W^{*} / E p$, where $\lambda$ is $e$-folding time of exponential decay of soil moisture anomaly, and $W^{*}$ field capacity. Though their definition of soil moisture and assumption of soil layer model were so simple, this relation between soil moisture anomaly persistency, field capacity of soil layer and $E p$ was partly proved in the observation in central Eurasia (Vinnikov and Yeserkepova 1991).
In recent years, more realistic and sophisticated land surface models (LSMs) have been developed, and many sensitivity experiments with GCMs have been conducted using different types of LSMs under different experimental designs. For example, Douville et al. (2001) and Douville (2002) assessed the influence of soil moisture on seasonal and interannual variability of Asian and African monsoons. Through some ensemble experiments with and without an interactive LSM (named ISBA; Interaction between Soil Biosphere and Atmosphere model), they found that the impact of soil moisture anomaly through the land-atmosphere interactive process is significant in relatively dry monsoon regions (e.g., Indian subcontinent and northeast Asia) but not in the humid monsoon regions (e.g., Southeast Asia). They also noticed that in the significant impact regions soil moisture anomaly primarily plays a role as an initial condition (at the monsoon onset phase) rather than the boundary condition. Kanae et al. (2006) also performed a set of hindcast GCM simulation (with prescribed sea surface temperature) on boreal summer hydro-climate for about 40 years (1951-1998), with and without realistic soil moisture anomalies, and noticed that only semi-arid regions in the peripheries of monsoon regions showed reasonably good simulated precipitation with the observed ones. It is interesting to note that all the GCM experiments, though the LCM performance and simulation design are quite different from each other, have shown relatively high impact of soil moisture anomaly in dry or semi-arid regions. This general tendency of soil-precipitation feedback has comprehensively been confirmed by the recent Global Land Atmosphere Coupling Experiment (GLACE) (Koster et al. 2004), where twelve GCMs with different LCMs participated. For example, in the Asian monsoon region, the sensitivity of precipitation change to soil moisture condition is large only in relatively dry areas, e.g., Indian subcontinent and the Yellow-River/Inner Mongolia in China as shown in Fig. 6. In humid monsoon and tropical regions, the impact seems to be small or insignificant primarily due to already-saturated soil moisture condition. However, this characteristic nature of weak soil moisture memory effect in the humid tropics may, to some extent, counteract with the relatively long memory effect in 

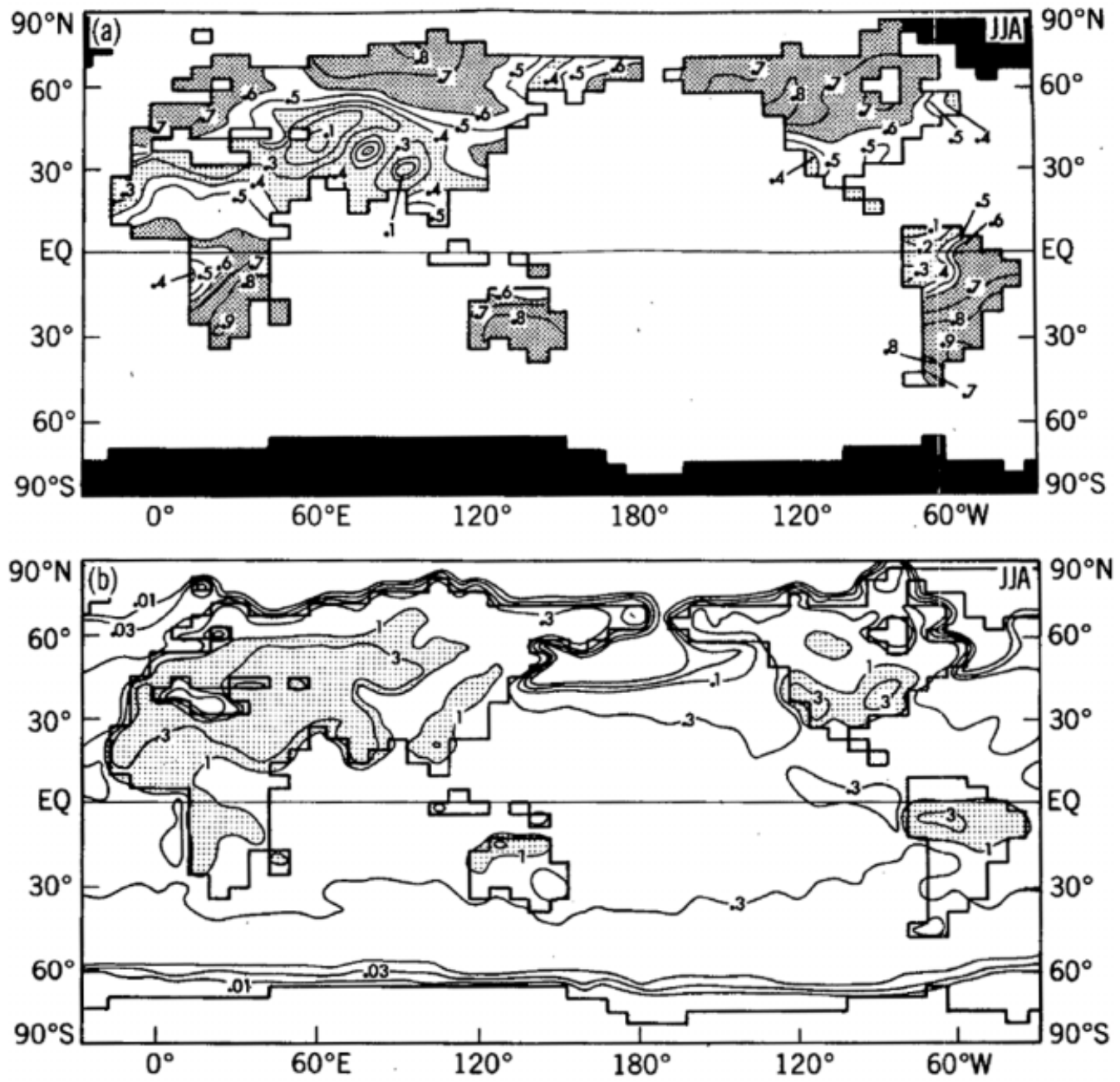

Fig. 5. (a) Lag one autocorrelation values of soil moisture for the months of June, July and August (JJA) for Soil Moisture Interactive GCM experiment (SMI). At each grid point, deviations of monthly mean soil moisture from the long-term mean for that month were correlated with data from the same grid point, but lagged one month. Coefficients greater than $0.16(0.3)$ are significantly different from zero at the $95 \%$ (99.9\%) confidence level. Values greater than 0.6 are densely stippled, while value less than 0.4 are lightly stippled. Permanently ice-covered region are black. (b) Potential evaporation ( $\mathrm{cm} \mathrm{d}^{-1}$ ) for JJA in SMI. (Delworth and Manabe 1989)

the humid tropics (Wu and Dickinson 2004). In addition, the soil moisture anomaly may be important as an initial condition to switch on the interaction with precipitation in these relatively dry regions.

\subsection{Role of vegetation}

Another important aspect of land-atmosphere interaction in addition to soil moisture (and snow cover) may be a role of vegetation. A general overview on the influence of vegetation on weather and climate is summarized in
Pielke et al. (1998). In the Asian monsoon region, most of the areas are heavily covered by vegetation, including tropical rain and monsoon forests, water-fed paddy field, grass land and boreal forest etc. The roles of vegetation in land-atmosphere interaction may be classified as follows;

1) control of radiation and energy fluxes through albedo and roughness

2) control of transpiration through stomatal resistance 


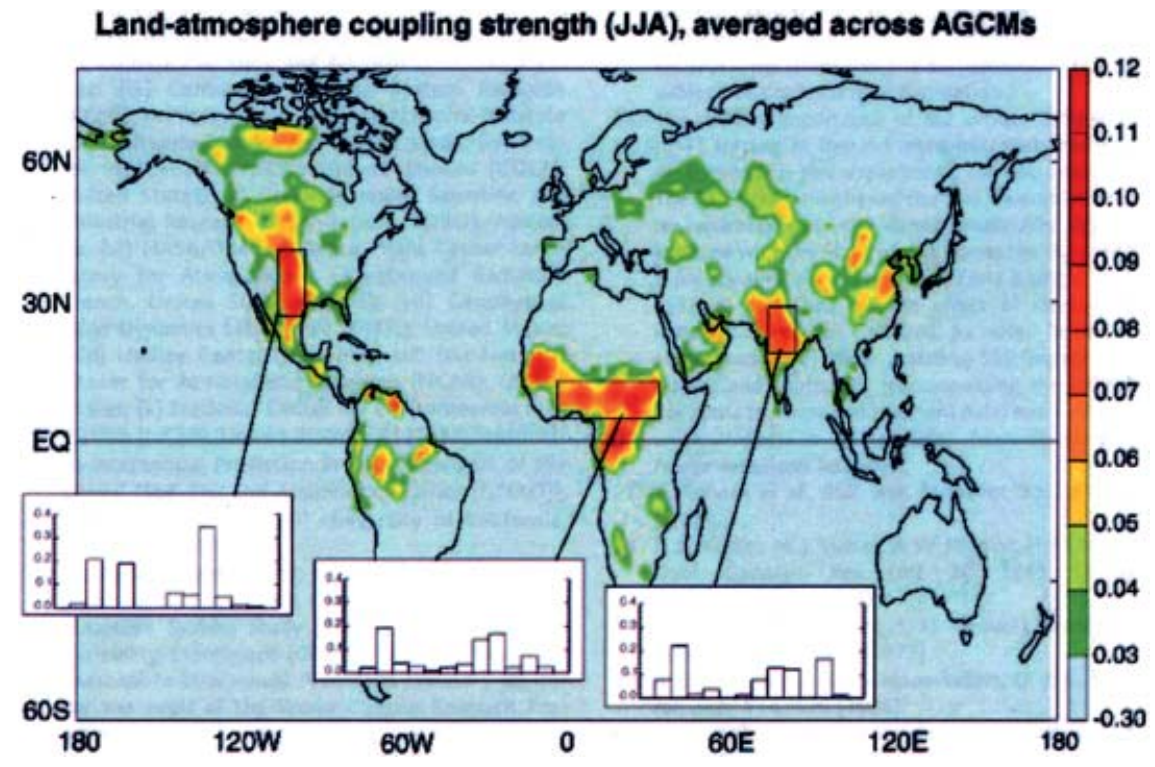

Fig. 6. The land-atmosphere coupling strength diagnostic for boreal summer (the $\Omega$ difference, dimensionless, describing the impact of soil moisture on precipitation), averaged across the 12 models participating in GLACE. (Insets) Area-averaged coupling strengths for the 12 individual models over the outlined, representative hotspot region. No signal appears in southern South America or at the southern tip of Africa. (Koster et al. 2004)

3) control of substantial field capacity of soil with root depth and structure

Due to lack of observations particularly in the large-scale vegetation and its impact on climate and water cycle, this aspect has been noted only in the recent years. LSMs including these vegetation processes have also been developed and improved in the recent few decades or so (e.g., Dickinson and Henderson-Sellers 1988; Sellers et al. 1986; Takata et al. 2003), though these models need numerous number of tuning parameters. To improve and fully utilize these sophisticated models, however, observational studies are also essential, including optimal determination of these parameter values. In the Asian monsoon region, intensive field campaigns related to some international projects such as GAME have been conducted, and have revealed new aspects of the role of vegetation in terms of energy and water cycle processes.

In the evergreen tropical forest in Thailand, energy and water flux measurements at several sites with different types of vegetation were conducted for more than two years as part of GAME-Tropics. The evapotranspiration esti- mated by a multi-layer model forced by the observed radiation, leaf area index (LAI) and other realistic parameters revealed that a seasonally maximum evapo-transpiration appeared in the late dry season just before the monsoon onset (Fig. 7) when the ground surface was driest in the year (Tanaka et al. 2003). A LSM study including the effect of root depth to pump up water in deep soil layer could well simulate this seasonal feature when the mean root depth was set at $6 \mathrm{~m}$ (Tanaka et al. 2004; Tanaka and Hashimoto 2006). This implies that effective field capacity must be set at an extremely large value in this case. In the deciduous monsoon forest in Thailand, in contrast, the seasonal maximum of evapotranspiration appeared in late monsoon season, associated with seasonal photosynthetic activity and water availability (Toda et al. 2002). These dependencies of the seasonal variation of evapo-transpiration (i.e., latent heating) on dominant vegetation types may have a great impact on modeling of regional and large-scale climate and water cycle, particularly in the tropics.

In the boreal forest in Siberia, similar long- 

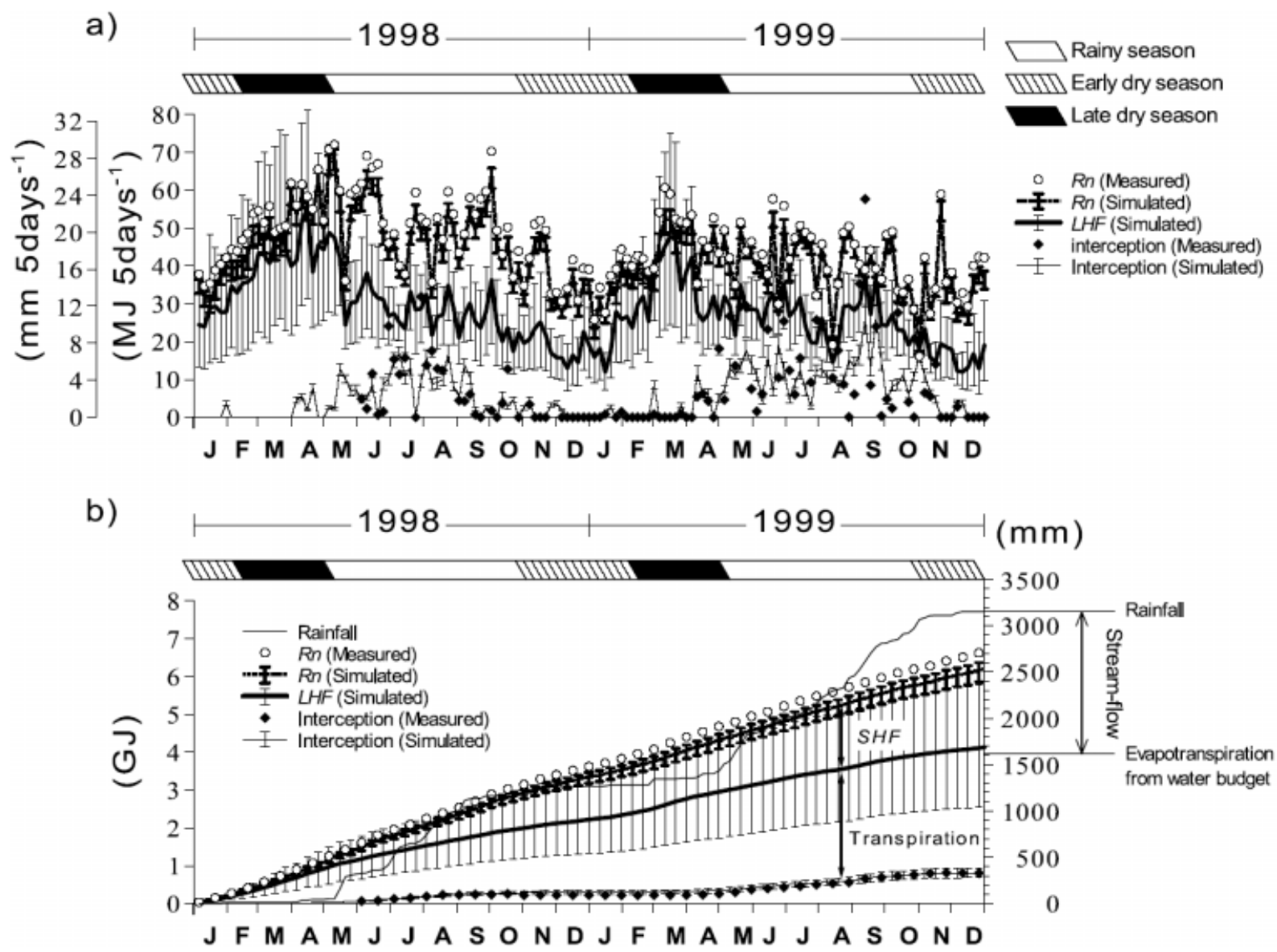

Fig. 7. (a) Seasonal variation of simulated net radiation, latent heat and rainfall interception over an evergreen forest of northern Thailand in 1998 and 1999. Observed variations of the same parameters except latent heat are also plotted. (b) The cumulative values of the same parameters and rainfall starting from January of 1998. Vertical bars indicate ranges of 32 simulated values with the maximum and the minimum, respectively. (Tanaka et al. 2003)

term flux measurements were made in Lena river basin as part of GAME-Siberia (Ohta et al. 2001) as shown in Fig. 8. Here, surface energy partition (sensible vs. latent energy) is strongly controlled by phenology of the (larch) forest coupled with seasonal melting (and freezing) condition of permafrost beneath the forest. Namely, in May during and after the snow melt sensible heating greatly increased, which was mostly used for melting the frozen ground. At the beginning of June when the melted layer of ground reaches about $20 \mathrm{~cm}$ depth or so, the foliation of trees suddenly started which at the same time triggered transpiration (latent heating) from the trees. During mid-summer (June, July and the beginning of August) latent heat- ing rate was comparable or more than sensible heating rate, and most of the annual precipitation occurs in this period. This condition prevailed for a broad area of Siberian boreal forest zone, which contributes to water recycling as well as maintenance of permafrost, by limiting the melting of permafrost within the nearsurface layer. Thus, the boreal forest and permafrost of this region are likely to co-exist as a symbiotic eco-climate system through energy and water cycle.

\section{Interaction between land-surface, $A B L$ and cloud/precipitation processes}

Impacts of land surface processes to the atmosphere are brought about through modifica- 


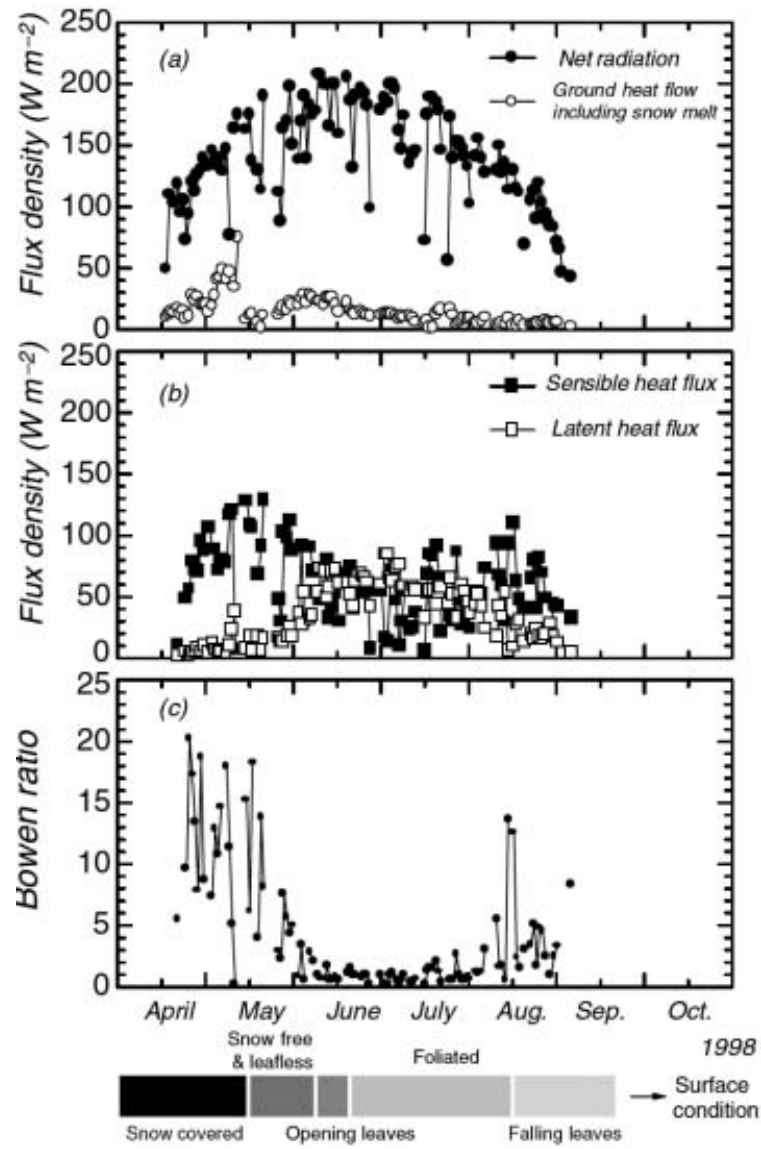

Fig. 8. Time-series for the daily net allwave radiation and the ground heat flow (a), the sensible heat flux and the latent heat flux (b), and the Bowen ratio (c) at a site of boreal forest (Taiga) near Yakutsk, East Siberia. The energy balance components and the Bowen ratio indicated in this figure are for a dry canopy only. (Ohta et al. 2001)

tion of the atmospheric boundary layer (ABL), and relevant cloud processes at or above the ABL. Betts et al. (1998) reviewed the overall possible interactive processes between land surface conditions and the ABL, and emphasized the importance of vegetation and related land cover/use differences on the ABL structure and cloud/precipitation process. In the monsoon region, the advection or inflow of moist flow from oceans to the land is sometimes emphasized to produce monsoon rainfall in the in the interior of the land area. However, through some continental-scale experiments (CSEs) under GEWEX (e.g., GAME in Asian monsoon region, The Large Scale Biosphere-Atmosphere Experiment in Amazonia (LBA)) moisture supply from wet land surface has also been proved to be important particularly in the late monsoon season when the surface becomes wetter than the earlier stage of the monsoon season. Shinoda and Uyeda (2002) examined a possible impact of water-fed paddy field in East Asia, using cloud-resolving atmospheric model. They forced the model using latent and sensible heat fluxes over the paddy field observed in GAMEHuaihe Basin Experiment (HUBEX), and found that meso-scale cloud systems embedded in the Meiyu (Baiu) front developed through moisture supply to ABL and change of moist static stability of the lower troposphere. The change of land-atmosphere interaction and its impact on cloud/precipitation systems through the seasonal change of soil moisture (surface wetness) condition was also observed over the Tibetan Plateau during the GAME-Tibet (Yamada and Uyeda 2006). Yamada (2007) simulated the feature over the plateau, showing that dry elevated surface on the Tibetan Plateau is favorable for more convective rain whereas wetter surface condition is favorable for stratiform cloud but with more rainfall amount as shown in Fig. 9. Understanding of these non-linear feedbacks from precipitation to land surface condition may have some clue for prediction of seasonal as well interannual variation of precipitation in the Asian monsoon region.

\section{Large-scale feedback processes through energy and water cycle}

A key process of regional climate and water cycle change by the land use/cover change including deforestation may be how the land surface change does induce changes of moisture convergence $(C)$ and in-situ evapotranspiration $(E)$ which result in change of precipitation $(P)$. This issue can be more generally interpreted as a fundamental energy and water cycle process of an interaction between an area-limited land surface condition and large-scale atmospheric environment or circulation. This issue was discussed in terms of deforestation in the Amazon basin by Zeng et al. (1996) and Zeng (1998). Figure 10 shows a schematic diagram of the two feedback loops in the perturbed land surface area in the atmospheric water cycle. 
(a) DRY
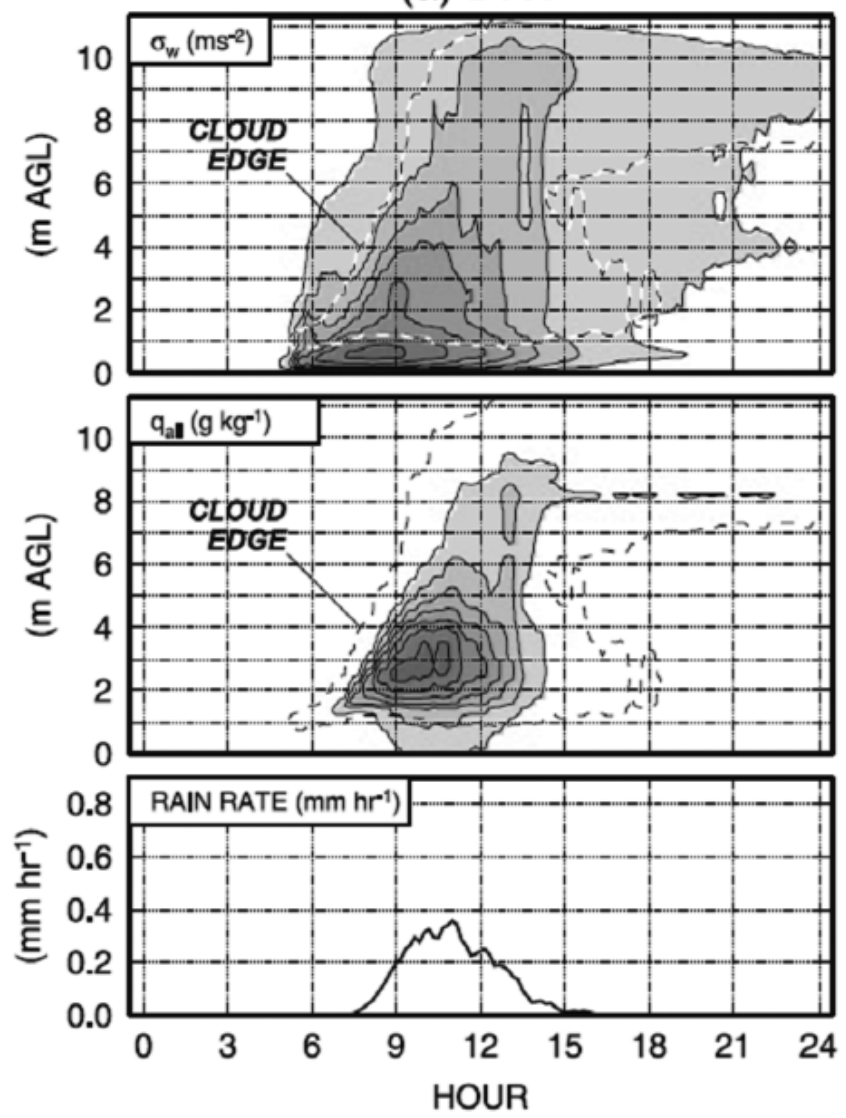

(b) WET
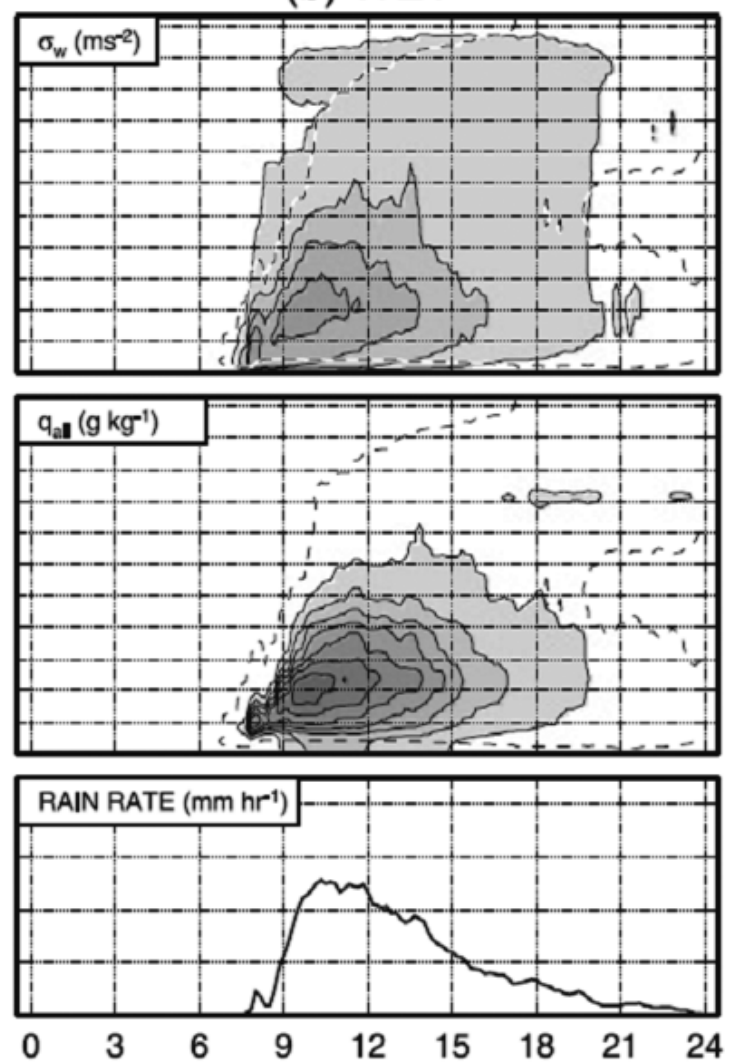

Fig. 9. Diurnal sequence of (top) the standard deviation of vertical velocity with contour interval of $0.2 \mathrm{~ms}^{-1}$, (middle) hydrometer mixing ration with contour interval of $2.0 \times 10^{-2} \mathrm{~g} \mathrm{~kg}^{-1}$, and (bottom) rain rate at the surface, averaged over the whole experimental domain in the (a) DRY and (b) WET experiments assumed in the summer monsoon season over Tibetan Plateasu. The broken lines in the top and middle panels indicate cloud edge, defined as the mixing ratio of cloud water and ice of $1.0 \times 10^{-4} \mathrm{~g} \mathrm{~kg}^{-1}$. (Yamada 2007)

Change in $P$ is controlled by two mechanisms: $C$ feedback (left hand side) and $E$ feedback (right hand side). In the first mechanism, an increase in $P$ releases latent heat that drives large-scale upward motion $(w)$, which causes more moisture convergence, leading to more $P$. In the $E$ feedback, higher $P$ leads to a wetter surface and more evaporation, which in turn contributes to even more $P$. If these two positive feedbacks overlap and work at the same time, a higher sensitivity of $P$ to land surface change appears. However, if the $P$ increase causes decrease in radiation through, for example, cloud cover increase, the increase of $C$ is partially compensated by decrease of $E$ due to decrease of radiation. An essential issue in the $C$ feedback may be how $P$ increase contributes to increase of large-scale upward motion $(w)$.

Assuming the thermodynamic balance neglecting the horizontal temperature advection, radiative heating approximated by Newtonian cooling, convective latent heating proportional to $P$, the moisture closure (i.e., $P=E+C$ ), and $C$ proportional to $w$ and humidity $q$ in the boundary layer, the $P$ change $(\Delta P)$ can be approximated as a simple equation as follows (Zeng et al. 1996; Zeng 1998):

$$
\Delta P=q € \Delta T^{*} /(1-q-\beta)
$$

where $q$ is a measure of moist static stability 


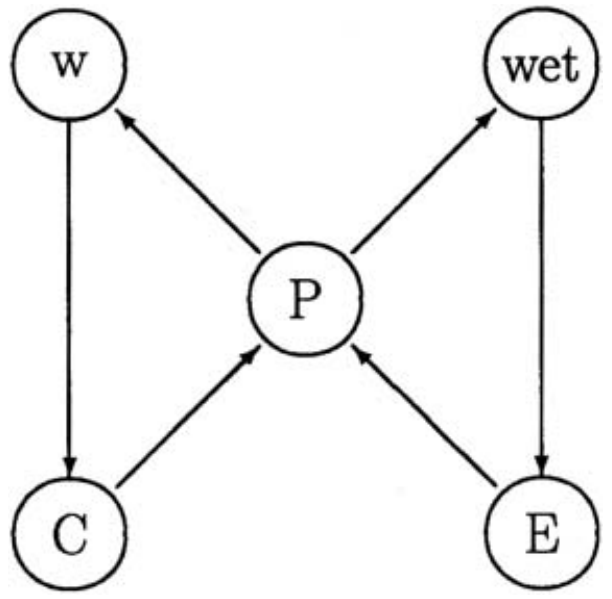

Fig. 10. The two major feedback loops in the perturbed region: moisture convergence feedback and evaporation feedback. Here, $P$ is precipitation, $w$ is large-scale upward motion, $C$ is largescale moisture convergence, wet is surface wetness, and $E$ is evapotranspiration. (Zeng 1998)

(unstable if $q>1$ ), $T^{*}$ is an atmospheric equilibrium temperature, $\beta\left(\equiv E p / P_{0}\right)$ is a ratio of potential evaporation $E p$ to a threshold precipitation rate $P_{0}$, above which soil is saturated. $€$ is a constant relevant to radiation relaxation and atmospheric latent heat profile.

In the tropics near the equator, this positive $C$ feedback roughly depends upon whether the horizontal scale of the perturbed area is larger than the equatorial radius of deformation (Zeng 1998). In the off-equatorial monsoon region, however, the influence of large-scale moisture advection is dominated and the feedback loops (as shown in Fig. 10) may not be so simple. The impact of deforestation may be apparent through the two positive feedback loops when the environmental monsoon flow is weak, as is demonstrated in September case of Thailand (Kanae et al. 2001) as described more in Section 7. In the relatively dry or marginalmonsoon region (e.g., the north-west part of Indian subcontinent, the Mongolia and northern China) where the sensitivity of $P$ to soil moisture anomaly is large as discussed in 4.2.2, the positive feedback loops as shown in Fig. 10 may be strong mostly due to large $\beta$ under relatively dry condition. We should keep in mind that relatively humid regions under the Asian summer monsoon climate, the atmospheric boundary layer and the lower troposphere are close to be saturated, that is, $q$ is relatively large. This condition also increases the sensitivity of $P$ under slight change of the surface condition (e.g., albedo), and in turn change of radiational forcing. The large impact of water-fed paddy field in China on development of cloud/precipitation system in the Meiyu frontal zone may correspond to this situation.

This simple model of energy and water balance can be applied in understanding the role of land atmosphere interaction of large-scale Asian monsoon system. For example, when we compare the pre-onset phase and the mature phase of the monsoon season, we notice that $\Delta P$ between the two season is basically due to change of $T^{*}$ derived from seasonal change of solar radiation, but the enhancement of the $P$ change is due to change of $q$ and $\beta$, derived from moisture convergence and in situ evaporation, respectively (Prasanna and Yasunari 2007). Without these moist processes, the large Asian monsoon system with huge $P$ particularly over land area may not be formed as it is.

\section{Relative role of large-scale orography vs. soil/vegetation cover on mean Asian monsoon climate}

Recently, we have conducted a series of GCM experiments assessing the role of continental land surface with and without vegetation, and relative importance of large-scale orography (e.g., Tibetan Plateau) and vegetation on the formation of Asian summer monsoon. In this case, various vegetation types are simply represented by difference in albedo, roughness and field capacity of surface soil layer (Yasunari et al. 2006). These experiments do not explicitly include the physiological processes of vegetation in the model, but the difference in field capacity of soil layer is expected to hold an important nature of vegetated or non-vegetated surface since the soil layer is basically produced by vegetation itself. The results suggest the role of vegetation is generally very large to produce strong monsoon as it is, and relative roles of albedo and field capacity of soil have appeared to be different from region to region. In East Asia both the Tibetan plateau topography 
a) South/Southeast Asia: Precipitation

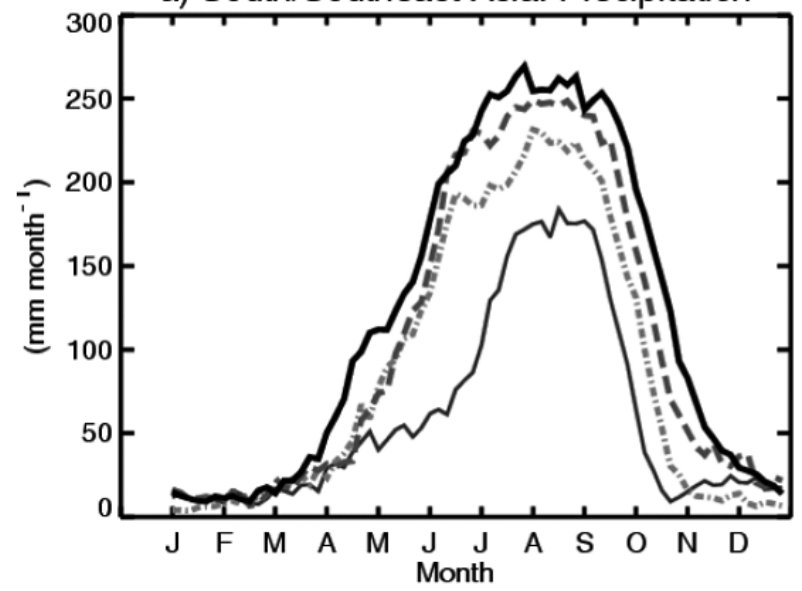

b) East Asia: Precipitation

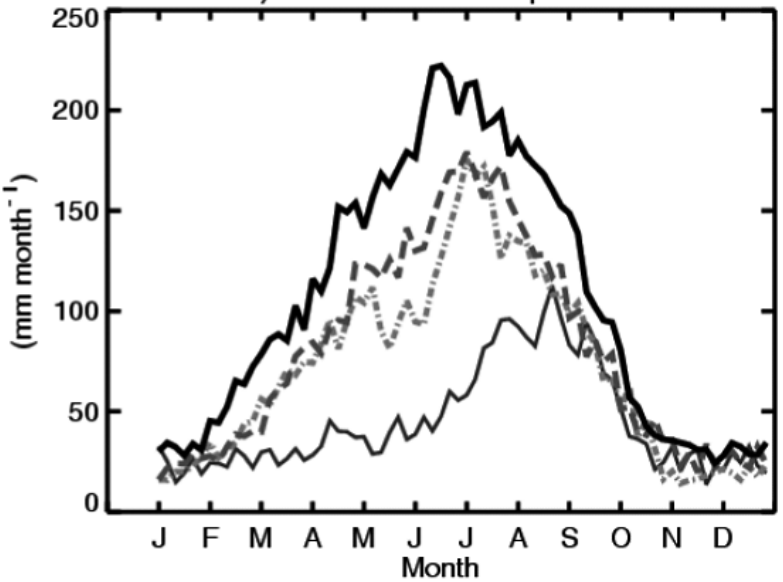

Fig. 11. Changes of seasonal precipitation for (a) South/Southeast Asia and (b) East Asia simulated by a CCSR/NIES/FRCGC atmospheric GCM for different boundary conditions of (1) no Tibetan Plateau, no vegetation (bared surface with rock albedo and roughness) (2) with Tibetan Plateau, but no vegetation, (3) with Tibetan Plateau and vegetation (soil only), and (4) with Tibetan Plateau with full vegetation (with soil and realistic vegetation albedo and roughness). (Yasunari et al. 2006)

and vegetation are important for penetration of moist monsoon flow and precipitation. In addition, relative importance of albedo vs. field capacity seems to be different from region to region. In the East Asia the albedo effect of vegetation is more important, but in the South and Southeast Asia the role of large field capacity has proved to be more important to produce the stronger monsoon particularly in the mid monsoon season, as shown in Fig. 11. These numerical experiments have strongly suggested that in the Asian monsoon region the role of vegetation is essential for the formation of monsoon circulation and precipitation through strong latent heating of the atmosphere. The evapo-transpiration from vegetated surface plays a crucial role in forming thick moist boundary layer and convection for the latent heating, as will be described in the next session. The analysis of the same GCM experiments for the northern Eurasia (Saito et al. 2006) proved that the Tibetan Plateau plays an important role to produce large amplitude of seasonal cycle with precipitation maximum in summer and that vegetation plays a crucial role to enhance in-situ water recycle there to produce summer precipitation basically from evapotranspiration.

\section{Land-atmosphere interaction in the seasonal cycle of monsoon}

The land shows strong and rapid heating (and cooling) in the seasonal cycle which in turn has a large impact on seasonal atmospheric differential heating (and cooling) processes between land and ocean. The land surface processes which modulate the seasonal heating, therefore, are likely to be responsible, to some extent, for interannual variability of the monsoons.

Seasonal land surface heating and resultant atmospheric heating over Eurasia manifest themselves in the surface or lower tropospheric pressure field. Figure 12 shows difference of monthly mean geopotential field at $850 \mathrm{hPa}$ from April to May. A remarkable decrease of pressure is seen over southern Eurasia centered over India/Tibetan Plateau area. Similar patterns of pressure change are seen over Eurasia from month to month for the period of March through July. In contrast, the pressure changes over the tropical and sub-tropical oceans are very small and positive (increase of pressure). The large decrease of pressure change over Eurasia indicates seasonal heating of land, centered over the Tibetan Plateau and 
- Climatological mean difference $(M a y-A p r)-$
$850 h P a[z(m), u(m / s), v(m / s)]$

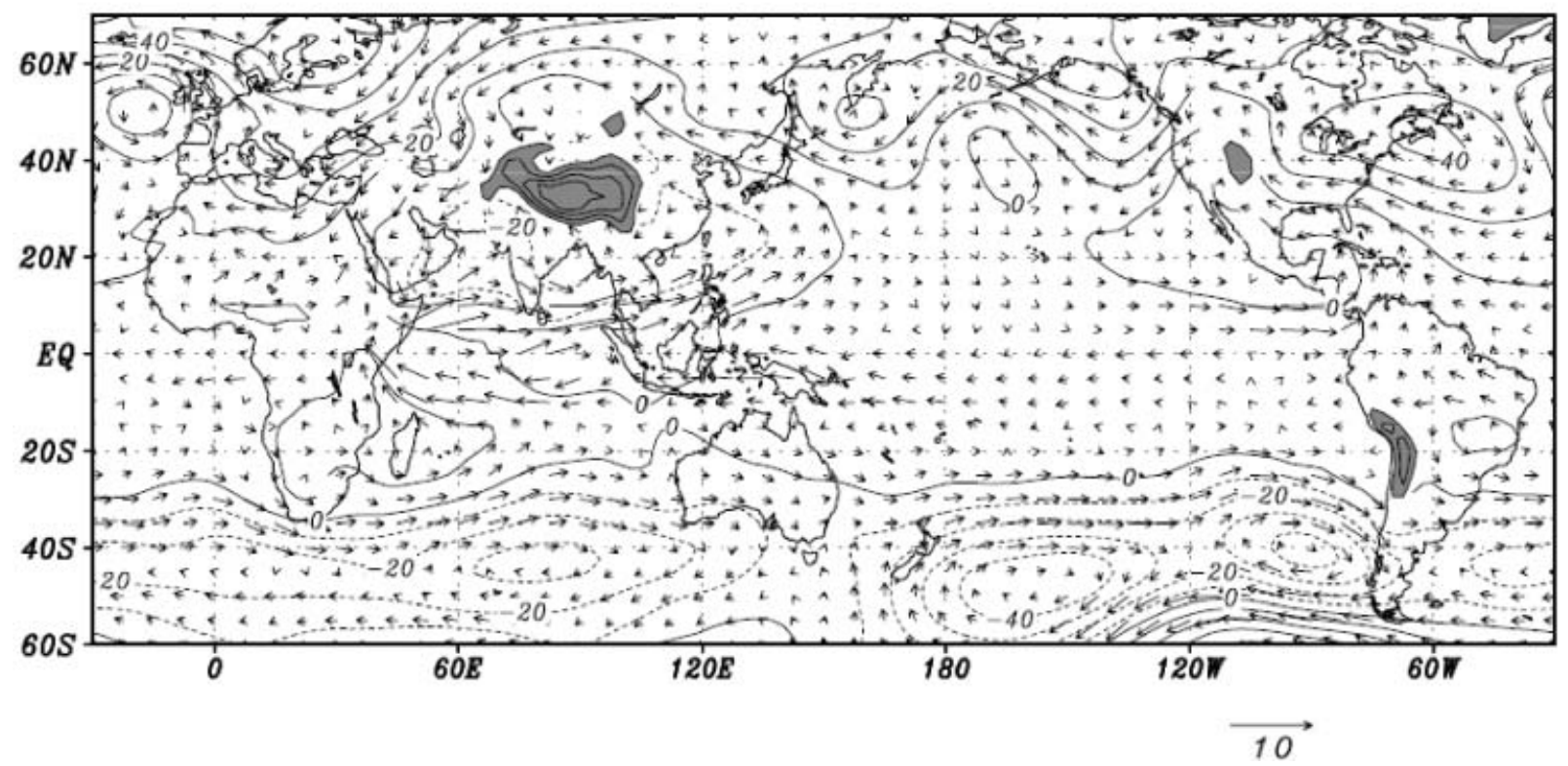

Fig. 12. Difference of climatological mean height at $850 \mathrm{hPa}$ and U, V field for May minus April by using 22 years (1979-2000) data of NCEP/NCAR reanalysis data. Dashed lines show negative values. Unit of contour is gpm. Unit of UV field is shown in the right bottom. (Yasunari, 2006)

Mongolia. The decrease of pressure over North America centered over the Rockies is very small, suggesting smaller heating over there compared to the Tibetan Plateau area.

The low-pressure area over the southern Eurasia (called the "monsoon trough") at the surface and lower troposphere induces moist southwesterly wind from the Indian Ocean (the southwest monsoon flow) toward India, Southeast Asia and East Asia, and dry northerly wind from the interior of the Eurasian continent. The moist monsoon flow, in turn, induces convection and precipitation over the southeastern part of the continent, which plays a dominant role of atmospheric latent heating as a "moist L-AI" during the monsoon season.

An important issue may be how this moist L-AI starts in the interior of the continent. The sensible heating over the Tibetan Plateau may be one of the important factors for triggering this process. In other continents, dry L-AI based on sensible heating from the land surface cannot produce the continental-scale monsoons.
Figure 13 shows a schematic diagram of this dry and shallow L-AI. This process is dominated over the Australian continent and the West Africa (to the north of West African monsoon) where desert area prevails and largescale downward motion is dominated. The existences of the desert and the downward motion are self-perpetuating through a positive feedback of surface albedo and radiation balance (Otterman 1974; Charney 1975; Webster et al. 1998). This dry L-AI cannot induce deep atmospheric heating in the interior of the continents, but can trigger shallow coastal monsoon circulation along the periphery of the continent. This shallow monsoon circulation, however, is likely to trigger deep convection when the continents are surrounded by warm tropical oceans, e.g., the warm water pool of Arafura and Timor seas neighboring to the Australian Continent (Kawamura et al. 2002). The land heating process over the Australian continent is thus important for triggering the IndonesiaAustralian monsoon. 

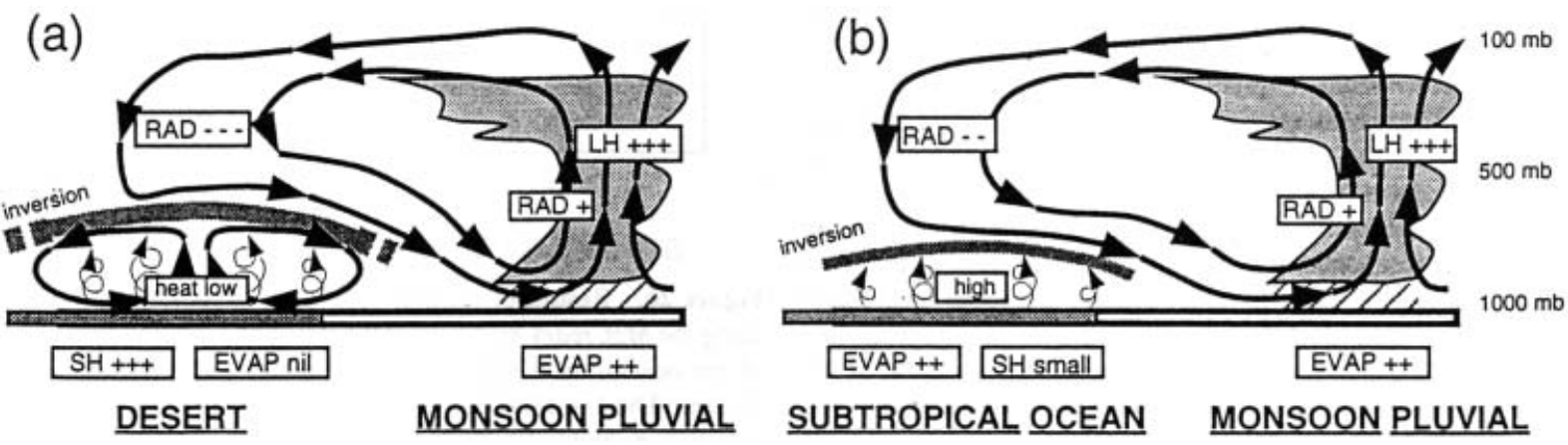

Fig. 13. Schematic of the circulation between (a) the desert region of North Africa and the Near East; and, (b) the subtropical ocean regions and the precipitating (pluvial) part of the monsoon circulation, respectively. The dominant heating or cooling terms are shown in the boxes. "SH" and "LH" refer to sensible and latent heating. "RAD" and "EVAP" refer to radiational heating and evaporation, respectively. The pluses and minuses represent the sign of the processes and their relative intensity. (Webster et al. 1998)

Over the elevated land surface of the Tibetan Plateau, in contrast, sensible heating plays a dominant role of atmospheric diabatic heating of the whole troposphere particularly in the onset phase of the Asian monsoon. Based upon the GAME-reanalysis data, Ueda et al. (2003) shows strong diabatic heating rate $(Q 1)$ in May through the whole troposphere over the Tibetan Plateau, suggesting that both sensible heating through deep dry convection but also latent heating through shallow convection in the pre-monsoon season play an important role in the heating process even in the pre-onset phase. The simulation of Asian monsoon by a coupled ocean-atmosphere GCM also suggest that without the Tibetan Plateau orography the monsoon precipitation cannot penetrate into the interior of the continent (Abe et al. 2003).

Diabatic heating over the Tibetan Plateau in the pre-monsoon phase causes horizontal temperature (pressure) gradient in the upper (lower) troposphere between the surrounding the Indian and Pacific Oceans and the interior of the continent, which facilitate large-scale convective activity over the South China Sea through the strengthening of the southwest monsoon flow intrusion (Ueda and Yasunari 1998). In addition, recent studies (e.g., Drbohlav and Wang 2004; Jiang et al. 2004; Wang et al. 2006; Waliser 2006) pointed out an important role of the existence of strong vertical east- erly wind shear over South Asia to the south of the Tibetan Plateau in the northward migration of convective zone with intraseasonal time-scales (including the monsoon onset phase) from the equatorial Indian Ocean toward the Himalayas. This may imply that the atmospheric diabatic heating over and around the Tibetan Plateau (which is primarily responsible for producing the meridional thermal contrast and the vertical easterly shear over South Asia) is one of the essential elements, which characterize the intraseasonal variability as well as the seasonal march of the Asian summer monsoon system.

\section{Possible impact of anthropogenic land use/cover change on Asian monsoon climate}

The Asian monsoon region is heavily populated with nearly $60 \%$ of the people on the earth are living. Therefore, the anthropogenic land use and land cover changes have been one of the largest in the world. These land use/cover changes from the original vegetation has a high possibility to have changed regional climate and water cycle of this region. Fu (2003) investigated potential impacts of human-induced land cover change on the East Asian monsoon, assuming the present and the potential vegetation (Ojima 2000). Using a regional model (MM5) with a land surface scheme (BATS), he noticed that the land cover change occurred in 
the history of China may have weakened the East Asian summer monsoon and strengthened the winter monsoon. The weakened monsoon trough in the interior of the continent presumably induced by decreased latent heating is responsible for the weakened summer monsoon.

The potential role of large-scale vegetation and land cover on Asian monsoon has recently been investigated also by some GCM experiments. Xue et al. (2004) showed that some characteristic features of the East Asian summer monsoon, e.g., abrupt northward jump of rainfall belt in the seasonal march and lowlevel monsoon circulation, are far better simulated when they introduced more sophisticated vegetation scheme of $\mathrm{SSiB}$ with realistic vegetation distribution than a simple vegetation scheme without physiological processes (i.e., photosynthesis and stomatal control of transpiration). The abrupt northward jump of rainfall could occur due to strong sensible heating in the interior of East Asia which induced horizontal temperature and pressure gradient in the pre-monsoon season. This probably was related to suppressed evapo-transpiration in the dry and hot season through stomatal control, resulting in enhancement of sensible heating. Suh and Lee (2004) also showed in the regional climate model experiment that temperature and rainfall biases over East Asia have improved considerably by including the biospheric processes of realistic vegetation over the East Asian landmass. These experiments have suggested that physiological control of surface energy flux partitioning (i.e., Bowen ratio) greatly affect pressure gradient over land, and in turn, circulation and rain systems. However, the reality of these biospheric processes needs to be validated through in-situ and satellite-based comprehensive observations.

Xue (1996) focused on the impact of desertification in the Mongolian and the inner Mongolian grassland on East Asian monsoon climate, by changing the area of desertification in the GCM. He found that the desertification is further intensified by altering from the grasslandtype to the desert-type land surface due to the reduction in evaporation and convective latent heating above the surface layer. This process seems to be contrastive to the positive feedback of desertification in the Sahel, West Africa where enhanced radiative cooling and associ- ated sinking motion induced by increased albedo is likely to be a main mechanism (Charney 1975).

In the Indo-china peninsula, a decreasing trend of monsoon rainfall has been remarkably seen only in September during the past several decades. Kanae et al. (2001) tried to explain this feature as a result of deforestation in the central part of the peninsula using a regional climate model (RAMS). They noticed that the effect of deforestation by changing albedo, roughness and soil moisture condition significantly reduced rainfall only in September when the monsoon westerly flow seasonally became weak considerably as shown in Fig. 14. In other monsoon months, the effect of the deforestation was negligible because the effect of strong inflow and convergence of moist monsoon flow was dominated over this region. These results suggested that the impact of land surface condition, i.e., vegetation cover, soil moisture etc., changes depending upon the atmospheric conditions including large-scale wind field, thermal stability etc.

\section{Concluding remarks}

This paper has discussed the landatmosphere interaction associated with the Asian monsoon climate and its variability. Particular emphasis and focus has been put on what are essential and primary roles of "land" of the Asian (or Eurasian) continent in the Asian monsoon system as a huge coupled ocean-land-atmosphere system.

As major land surface parameters controlling the Asian monsoon variability, we have discussed roles of snow cover, soil moisture and vegetation. The snow cover and soil moisture are internal factors of the climate system particularly in the seasonal to interannual time scales, and are likely to play some important roles in changing large-scale surface energy and water balance, which in turn affect the monsoon circulation and precipitation. One big problem is that the data availability of these two quantities as the internal parameters of the climate system is still limited though the new satellite data are considerably improving the situation. Recently, new attempts have started on land-surface assimilation using satellite and in-situ observational data and land surface models (e.g., Pathemathevamn et al. 

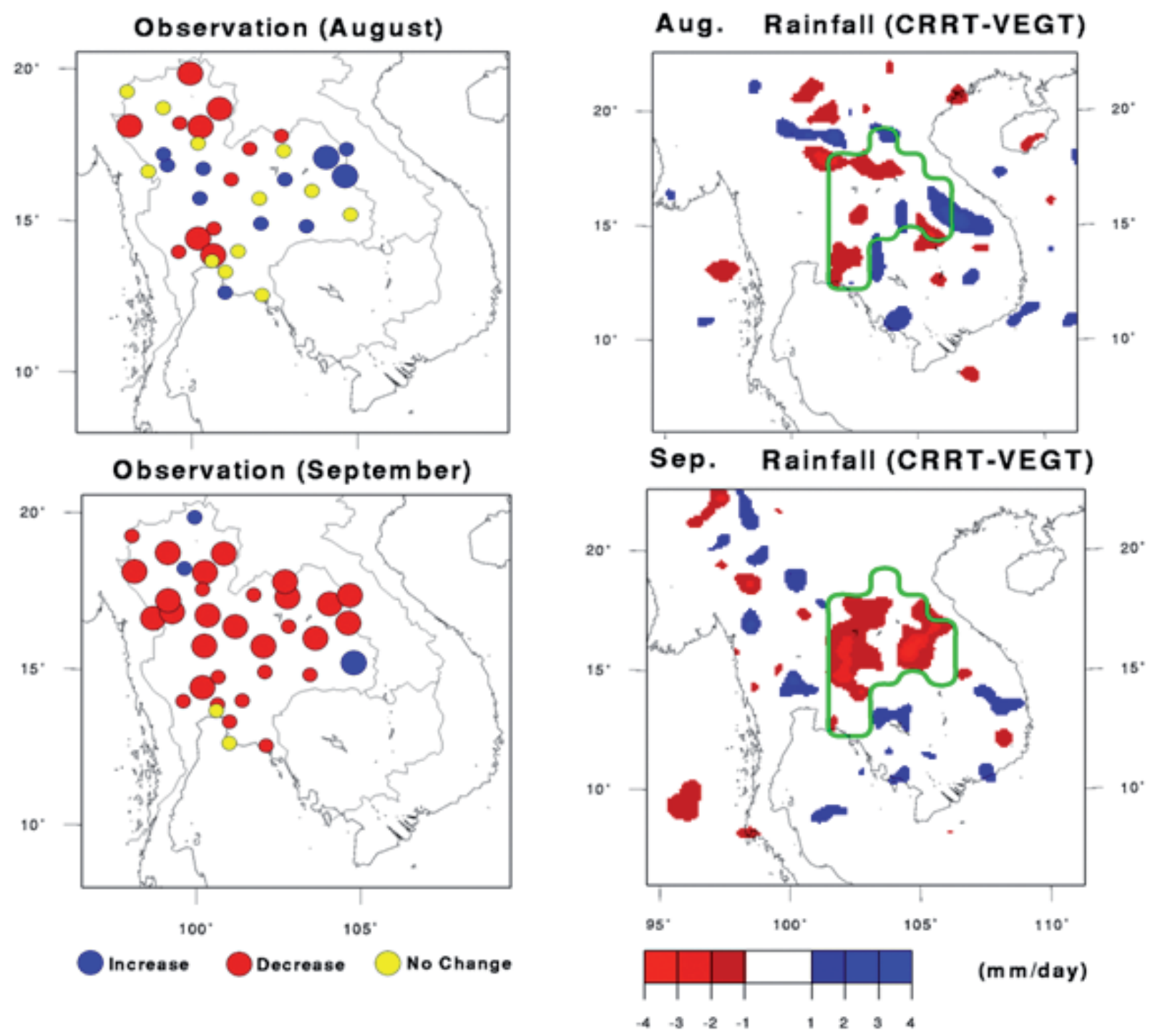

Fig. 14. Observed rainfall trend during 1950-1990 in August (left, upper) and September (left, lower) and rainfall difference in August (right, upper) and September (right, lower) in Indo-China peninsula computed between vegetated condition and deforested condition in a regional atmospheric modeling system (RAMS). Blue (red) colour shows increasing trend or positive values, and size of circles in the left column shows trend values. (Kanae et al. 2001)

2003; Boussetta et al. 2005), which are expected to produce better data for assessing land-atmosphere interaction in the near future.

The quantitative estimates of the impact of these parameters on the monsoon-related fields need further study, but it may be concluded how and to what extent these parameters play a role in variability of the monsoon system depends strongly on basic climatic condition and seasonality. From the modeling as well as ob- servational studies the snow cover is likely to influence atmosphere essentially through the albedo effect particularly in lower latitudes and the Tibetan Plateau. From the GCM experiments it has been strongly suggested that soil moisture anomalies efficiently affect the atmosphere under dry or semi-arid condition, but this effect needs further assessment including vegetation effect, since soil layer usually exist with vegetation in the real nature. 
Another parameter, vegetation, has been noted as an important variable for the formation of moist monsoon flow over the continent. Vegetation has several functions for controlling atmospheric energy and water vapor conditions, such as albedo, roughness, stomatal conductance and water-holding capacity of root/soil structure. In fact, through the recent observations and modeling studies, it has been noticed that the atmospheric latent heating over land is fundamentally through vegetation control of evapo-transpiration.

The role of the Tibetan Plateau is emphasized to trigger the atmospheric heating over the continent. At the onset or pre-monsoon phase of the monsoon, sensible heating over the elevated land surface plays an important role to form the continental-scale heat low in the lower troposphere. This circulation system in turn produces moist southwesterly flow penetrating into the south, southeast and East Asia. This moist monsoon flow induces convection and precipitation over the southeastern part of the continent, which further intensifies atmospheric diabatic heating through latent heat release. In addition, we emphasized that the moist land surface could play an important role for the penetration of precipitation deep interior of the continent. This moist land surface process is essentially attributed to the existence of vegetation. In this sense, the heavily vegetated land surface may be another key factor contributing to the huge Asian summer monsoon system, in addition to the Tibetan Plateau.

Through the GCM and RCM experiments the anthropogenically-induced change of land cover/use including the deforestation has proved to be a great impact on regional precipitation and water cycle of the monsoon region by changing some characteristics of vegetation control of energy and water cycle, which in turn affect $\mathrm{ABL}$ and cloud/precipitation processes in regional-scale. The discussion has also been made on how the land surface changes could induce change of precipitation through feedback processes of moisture convergence and in-situ evapo-transpiration processes. The critical role of moisture amount near surface and in the ABL is emphasized, to induce positive feedback to change of precipitation over land in the monsoon region.
In the Asian monsoon system, the fundamental heating centers are located over the warm oceans near the continent. The maintenance of this system is coupled with the strong thermal and thermo-dynamical effect of the Tibetan Plateau through the zonally-oriented giant circulation between the South Asia and the equatorial Pacific region (Kitoh 2002; Abe et al. 2004). It can be emphasized here that even the coupled atmosphere-ocean system in the tropical $\mathrm{Pa}$ cific, which is an essential part of the Asian/ Australian monsoon system, is strongly controlled by the land-atmosphere interaction over the Eurasian continent.

\section{Acknowledgements}

I would like to thank Dr. Jun Matsumoto for his careful reading of the manuscript and invaluable comments on this paper. Thanks are extended to Dr. Toshiki Iwasaki, editor in chief of the special issue for his encouragement on completing this paper.

\section{References}

Abe, M., A. Kitoh, and T. Yasunari, 2003: An evolution of the Asian summer monsoon associated with mountain uplift. - Simulation with the MRI atmosphere-ocean coupled GCM-. J. Meteor. Soc. Japan, 81, 909-933.

Abe, M., T. Yasunari, and A. Kitoh, 2004: Effects of large-scale orography on the coupled atmosphere-ocean system in the tropical Indian and pacific oceans in boreal summer. $J$. Meteor. Soc. Japan, 82, 745-759.

Bamzai, A.S. and J. Shukla, 1999: Relation between Eurasian snow cover, snow depth, and the Indian summer monsoon: An observational study. J. Climate, 12, 3117-3132.

Barnett, T.P., L. Dümenil, U. Schlese, E. Roeckner, and M. Latif, 1989: The effect of Eurasian snow-cover on regional and global climate variations. J. Atmos. Sci. 46, 661-686.

Betts, A.K., P. Viterbo, A. Beljaars, H.-L. Pan, S.-Y. Hong, M. Goulden, and S. Wofsy, 1998: Evaluation of land-surface interaction in ECMWF and NCEP/NCAR reanalysis models over grassland (FIFE) and boreal forest (BOREAS). J. Geophys. Res., 103, 23079-23086.

Blanford, H.F., 1884: On the connection of the Himalaya snowfall with dry winds and seasons of drought in India. Proc. Roy. Soc. London, 37, $3-22$.

Bhanu Kumar, O.S.R.U., 1987: Seasonal variation of Eurasian snow cover and its impact on the 
Indian summer monsoon. IAHS Publ., 166, 51-60.

Bhanu Kumar, O.S.R.U., 1988: Interaction between Eurasian winter snow cover and location of the ridge at the $500 \mathrm{hPa}$ level along $75^{\circ} \mathrm{E}$. $J$. Meteor. Soc. Japan, 66, 509-514.

Boussetta, S., T. Koike, M. Pathmathevan, and K. Yang, 2005: Investigation of the effect of a coupled land-atmosphere satellite data assimilation system on land-atmosphere processes, Predictions in Ungauged Basins: Promises and Progress. IAHS publ. 303.

Chattopadhyay, J. and G.P. Singh, 1995: A reappraisal of relationships between northern hemispheric surface air temperatures and Indian summer monsoon rainfall. Theor. Appl. Climatol., 52, 169-175.

Charney, J.G., 1975: Dynamics of deserts and droughts in Sahel. Quart. J. Roy. Meteor. Soc., 101, 193-202.

Delworth, T. and S. Manabe, 1988: The influence of potential evaporation on the variabilities of simulated soil wetness and climate. J. Climate, 1, 523-547.

Delworth, T. and S. Manabe, 1989: The influence of soil wetness on near-surface atmospheric variability. J. Climate, 2, 1447-1462.

Dey, B. and O.S.R.U. Bhanu Kumar, 1982: An apparent relationship between Eurasian spring snow cover and the advance period of the Indian summer monsoon. J. Appl. Meteor., 21, 1929_ 1932.

Dickinson, R.E. and A. Henderson-Sellers, 1988: Modeling tropical deforestation: A study of GCM land-surface parameterizations. Quart. J. Roy. Meteor. Soc., 114, 439-462.

Dickson, R.R., 1984: Eurasian snow cover versus Indian monsoon rainfall-An extension of the Hahn-Shukla results. J. Climate Appl. Meteor., 23, 171-173.

Douville, H. and J.-F. Royer, 1996: Sensitivity of the Asian summer monsoon to an anomalous Eurasian snow cover within the Meteo-France GCM. Clim. Dyn., 12, 449-466.

Douville, H. et al., 2001: Influence of soil moisture on the Asian and African monsoon. Part I. Mean monsoon and daily precipitation. J. Climate, 14, 2381-2403.

Douville, H., 2002: Influence of soil moisture on the Asian and African monsoon. Part II. Interannual variability. J. Climate, 15, 701-720.

Drbohlav, H.-K.L. and B. Wang, 2005: Mechanism of the northward propagating intraseasonal oscillation in the south Asian monsoon region: Results from a zonally-averaged model. $J$. Climate, 18, 952-972.
Fu, C.-B., 2003: Potential impacts of human-induced land cover change on east Asian monsoon. Global Planetary Change, 37, 219-229.

Gong, G., D. Entekhabi, J. Cohen, and D. Robinson, 2004: Sensitivity of atmospheric response to modeled snow anomaly characteristics. $J$. Geophys. Res., 109, D06107, doi:10.1029/ 2003JD004160.

Hahn, D.G. and J. Shukla, 1976: An apparent relationships between Eurasian snow cover and Indian monsoon rainfall. J. Atmos. Sci., 33, 2461-2462.

Jiang, X., T. Li, and B. Wang, 2004: Structure and mechanisms of the northward propagating boreal summer intraseasonal oscillation. J. Climate, 17, 1022-1039.

Kanae, S., Y. Hirabayashi, T. Yamada, and T. Oki, 2006: Influence of "realistic" land surface wetness on predictability of seasonal precipitation in boreal summer. J. Climate, 19, 1450-1460.

Kanae, S., T. Oki, and K. Musiake, 2001: Impact of Deforestation on Regional Precipitation over the Indochina Peninsula. J. Hydrometeorol., 2, 51-70.

Kawamura, R., 1998: A possible mechanism of the Asian summer monsoon-ENSO coupling. $J$. Meteor. Soc. Japan, 76, 1009-1027.

Kawamura, R., Y. Fukuta, H. Ueda, T. Matsuura, and S. Iizuka, 2002: A mechanism of the onset of the Australian summer monsoon. J. Geophys. Res., 107 (D14), doi:10.1029/ 2001JD001070.

Kahndekar, M.L., 1991: Eurasian snow cover, Indian monsoon and El Niño/Southern Oscillation. Asynthesis. Atmos. Ocean, 29, 636-647.

Kitoh, A., 2002: Effects of Large-Scale Mountains on Surface Climate-A Coupled OceanAtmosphere General Circulation Model Study. J. Meteor. Soc. Japan, 80, 1165-1181.

Koike, T., H. Fujii, T. Ohta, and E. Togashi, 2001: Development and validation of TMI algorithms for soil moisture and snow. Remote Sensing and Hydrology 2000, IAHS publ., 267, 390393.

Koster, et al. (The GLACE Team), 2004: Regions of strong coupling between soil moisture and precipitation. Science, 305, 1138-1140.

Kripalani, R.H., S.V. Singh, A.D. Vernekar, and V. Thapliyal, 1996: Empirical study on Nimbus-7 snow mass and Indian summer monsoon rainfall. Int. J. Climatol., 16, 23-34.

Kripalani, R.H. and A. Kulkarni, 1999: Climatology and variability of historical Soviet snow depth data: Some new perspectives in snow-Indian monsoon teleconnections. Clim, Dyn., 15, 475489 . 
Kripalani, R.H., A. Kulkarni, and S.S. Sabade, 2003: Western Himalayan snow cover and Indian monsoon rainfall: A re-examination with INSAT and NCEP/NCAR data. Theor. Appl. Climatol., 74, 1-18.

Liu, X. and M. Yanai, 2002: Influence of Eurasian spring snow cover on Asian summer rainfall. Int. J. Climatol., 22, 1075-1089.

Manabe, S., 1969: Climate and the Ocean circulation, I. The atmospheric circulation and the hydrology of the earth's surface. Mon. Wea. Rev., 97, 739-774.

Morinaga, Y., M. Shinoda, and T. Yasunari, 1997: Relationships between spring snow cover over central Asia and Indian summer monsoon rainfall. Proc. of the Third USA / CIS Joint Conference on Environmental Hydrology and Hydrogeology, 245-250.

Morinaga, Y., K. Masuda, M. Nishimori, and T. Yasunari, 2000: Relationships between Eurasian snow cover and the Indian summer monsoon rainfall. Proc. of the (International Conference on Climate Change and Variability-Past, Present and Future-, Tokyo, Japan) 293298.

Ohta, T., T. Hiyama, H. Tanaka, T. Kuwada, T.C. Maximov, T. Ohata, and Y. Fukushima, 2001: Seasonal variation in the energy and water exchanges above and below a larch forest in eastern Siberia. Hydrological. Processes, 15(8), $1,459-1,476$.

Ojima, D., 2000: Land use/lane cover change in temperate East Asia: current status and future trend. International START Secretariat, Washington DC, USA, p. 228.

Otterman, J., 1974: Baring high-albedo soils by overgrazing, a hypothesized desertification mechanism. Science, 186, 426-427.

Pathemathevamn, M., T. Koike, and X. Li, 2003: A New Satellite Based Assimilation Algorithm to Determine Spatial and Temporal Variations of Soil Moisture and Tempretaure Profiles. J. Meteor. Soc. Japan, 81, 1111-1135.

Prasanna, V. and T. Yasunari, 2007: Time-space characteristics of seasonal and interannual variations of atmospheric water balance over South Asia. Submitted to. J. Meteor. Soc. Japan.

Pielke, et al., 1998: Interactions between the atmosphere and terrestrial ecosystems: influence on weather and climate. Global Change Biology, 4, 461-475.

Robock, A., C.A. Schlosser, K.Y. Vinnikov, N.A. Speranskaya, J.K. Entin, and S. Qiu, 1998: Evaluation of the AMIP soil moisture simulations. Global Planetary Change, 19, 181-208.
Robock, A., K.Y. Vinnikov, G. Srinivasan, J.K. Entin, S.E. Hollinger, N.A. Speranskaya, S. Liu, and A. Namkhai, 2000: The Global Soil Moisture Data Bank. Bull. Amer. Meteor. Soc., 81, 1281-1299.

Robock, A., M. Mu, K. Vinnikov, and D. Robinson, 2003: Land surface conditions over Eurasia and Indian summer monsoon rainfall. J. Geophy. Res., 108, 4131.

Saito, K., T. Yasunari, and K. Takata, 2006: Relative roles of large-scale orography and vegetation on global hydro-climate. Part II. Impacts on hydro-climate over the Eurasian continent. J. Hydrometeor., 7, 642-659.

Sellers, P.J., Y. Mintz, Y.C. Sud, and A. Dalcher, 1986: A simple biosphere model ( $\mathrm{SiB}$ ) for use within general circulation models. J. Atmos. Sci., 43, 505-531.

Shankar-Rao, P., K.M. Lau, and S. Yang, 1996: On the relationship between Eurasian snow cover and the Asian summer monsoon. Int. J. Climatol., 16, 605-616.

Shen, X., M. Kimoto, and A. Sumi, 1998: Role of land surface processes associated with interannual variability of broad-scale Asian summer monsoon as simulated by the CCSR/NIES AGCM. J. Meteor. Soc. Japan, 76, 217-236.

Shinoda, M. and M. Gamo, 2000: Interannual variations of boundary layer temperature over the African Sahel associated with vegetation and upper-troposphere. J. Goephys. Res., 105, 12317-12327.

Shinoda, M., H. Utsugi, and W. Morishima, 2001: Spring snow-disappearance timing and its possible influence on temperature fields over central Eurasia. J. Meteor. Soc. Japan, 79, 37-59.

Shinoda, M., Y. Morinaga, and T. Yasunari, 2003: The forefront of monsoon researches. Meteor. Res. Notes (edi., by R. Kawamura), 204, 69114 (in Japanese).

Shinoda, T. and H. Uyeda, 2002: Effective Factors in the Development of Deep Convective Clouds over the Wet Region of Eastern China during the Summer Monsoon Season. J. Meteor. Soc. Japan, 80, 1395-1414.

Suh, M.-S. and D.-K. Lee, 2004: Impact of land use/ cover changes on surface climate over east Asia for extreme climate cases using RegCM2. J. Geophys. Res., 109, D020108, doi:10.1029/ 2003JD003681.

Takata, K. and M. Kimoto, 2000: A numerical study on the impact of soil freezing on the continental-scale seasonal cycle. J. Meteor. Soc. Japan, 78, 199-221.

Takata, K., S. Emori, and T. Watanabe, 2003: Development of the minimal advanced treatments of 
surface interaction an runoff. Global and Planetary Change, 38, 209-222.

Tanaka, K., H. Takizawa, N. Tanaka, I. Kosaka, N. Yoshifuji, C. Tantasirin, S. Piman, M. Suzuki, and N. Tangtham, 2003: Transpiration peak over a hill evergreen forest in northern Thailand in the late dry season: Assessing the seasonal changes in evapotranspiration using a multilayer model. J. Geophys. Res., 108(D17), 4533, doi:10.1029/2002JD003028.

Tanaka, K., H. Takizawa, T. Kume, J. Xu, C. Tantasirin, and M. Suzuki, 2004: Impact of rooting depth and soil hydraulic properties on the transpiration peak of an evergreen forest in northern Thailand in the late dry season. J. Geophys. Res., 109, D23107, doi:10.1029/ 2004JD004865.

Tanaka, K. and S. Hashimoto, 2006: Plant canopy effects on soil thermal and hydrological properties and soil respiration. Ecological Modelling, 196, 32-44.

Toda, M., K. Nishida, N. Ohte, M. Tani, and K. Musiake, 2002: Observation of Energy Fluxes and Evapotranspiration over Terrestrial Complex Land Covers in the Tropical Monsoon Region. J. Meteor. Soc. Japan, 80, 465-484.

Ueda, H., H. Kamahori, and N. Yamazaki, 2003: Seasonal contrasting features of heat and moisture budgets between the eastern and western Tibetan Plateau during the GAME IOP. J. Climate, 16, 2309-2324.

Ueda, H. and T. Yasunari, 1998: Role of warming over the Tibetan Plateau in early onset of the summer monsoon over the Bay of Bengal and the South China Sea. J. Meteor. Soc. Japan, 76, $1-12$.

Vernekar, A.D., J. Zhou, and J. Shukla, 1995: The effect of Eurasian snow cover on the Indian monsoon. J. Climate, 8, 248-266.

Vinnikov, K.Y. and I.B. Yeserkepova, 1991: Soil moisture: Empirical data and model results. $J$. Climate, 4, 66-79.

Walker, G.T., 1910: Correlation in seasonal variations of weather II. Mem. Indian Meteor. Dept., 21, Part 2, 22-45.

Walsh, J.E., W.H. Jasperson, and B. Ross, 1985: Influence of snow cover and soil moisture on monthly air temperature. Mon. Wea. Rev., 113, 756-768.

Wang, B., P. Webster, K. Kikuchi, T. Yasunari, and Y. Qi, 2006: Boreal summer quasi-monthly oscillation in the global tropics. Clim. Dyn., 27, $7 / 8,661-675$.

Waliser, D., 2006: Intraseasonal Variability. Chap. 5 in "The Asian Monsoon" edi. By B. Wang. Springer (Praxis Publishing), 203-257.
Webster, P.J., V.O. Magaña, T.N. Palmer, J. Shukla, R.A. Thomas, M. Yanai, and T. Yasunari, 1998: Monsoons: Processes, predictability, and the prospects for prediction. J. Geophys. Res., 103(C7), 14451-14510.

Wu, W. and R.E. Dickinson, 2004: Time scales of layered soil moisture memory in the context of land-atmosphere interaction. J. Climate, 17, 2752-2764.

Xue, Y., H.-M.H. Juang, W.-P. Li, S. Prince, R. DeFries, Y. Jiao, and R. Vasic, 2004: Role of land surface processes in monsoon development: East Asia and West Africa. J. Geophys. Res., 109, D03105, doi:10.1029/2003JD003556.

Xue, Y., 1996: The impact of desertification in the Mongolian and the Inner Mongolian Grassland on the regional climate. J. Climate, 9, 21732189.

Yamada, H. and H. Uyeda, 2006: Transition of the rainfall characteristics related to the moistening of the land surface over the Central Tibetan Plateau during the Summer of 1998. Mon. Wea. Rev., 134, 3230-3247.

Yamada, H., 2007: Numerical simulations of the role of land-surface conditions in the evolution and structure of summertime thunderstorms over a flat highland. Mon. Wea. Rev. in press.

Yamazaki, K., 1989: A study of the impact of soil moisture and surface albedo changes on Global Climate Using the MRI • GCM-I. J. Meteor. Soc. Japan, 67, 123-146.

Yang, S., 1996: ENSO-snow-monsoon associations and seasonal-interannual predictions. Int. J. Climatol., 16, 125-134.

Yang, S. and K.-M. Lau, 1998: Influences of Sea Surface Temperature and Ground Wetness on Asian Summer Monsoon. J. Climate, 11, 3230-3246.

Yang, S., K.M. Lau, S.-H. Yoo, J.L. Kinter, K. Miyakoda, and C.-H. Ho, 2004: Upstream subtropical signals preceding the Asian summer monsoon circulation. J. Climate, 17, 42134229.

Yasunari, T., 1987: Global structure of the El Niño/ Southern Oscillation. Part II: time revolution. J. Meteor. Soc. Japan, 65, 81-102.

Yasunari, T., 1991: The monsoon year-A new concept of the climatic year in the tropics. Bull. Amer. Meteor. Soc., 72, 1131-1138.

Yasunari, T., A. Kitoh, and T. Tokioka, 1991: Local and remote responses to excessive snow mass over Eurasia appearing in the northern spring and summer climate. -A study with the MRI • GCM-. J. Meteor. Soc. Japan, 69, 473487.

Yasunari, T. and Y. Seki, 1992: Role of the Asian 
monsoon on the interannual variability of the global climate system. J. Meteor. Soc. Japan, 70, 177-189.

Yasunari, T., 2006: Land-Atmosphere Interaction. Chap. 11 in "The Asian Monsoon" ed. By B. Wang. Springer (Praxis Publishing), 459-478.

Yasunari, T., K. Saito, and K. Takata, 2006: Relative Roles of large-scale orography and land surface processes on global hydro-climate. Part I. Impacts on monsoon systems and tropics. J. Hydrometeor., 7, 626-641.
Ye, H. and Z. Bao, 2001: Lagged teleconnections between snow depth in northern Eurasia, rainfall in Southeast Asia and sea-surface temperature over the tropical Pacific Ocean. Int. J. Climatol, 21, 1607-1621.

Zeng, N., R. Dickinson, and X. Zeng, 1996: Climatic impact of Amazon deforestation-A mechanistic model study. J. Climate, 9, 859-883.

Zeng, N., 1998: Understanding climate sensitivity to tropical deforestation in a mechanistic model. J. Climate, 11, 1969-1975. 